\title{
Commentary: Platelet-rich plasmapheresis in aortic dissection repair: New data for an old technique
}

\author{
Nicholas D. Andersen, MD
}

From the Division of Cardiovascular and Thoracic Surgery, Duke University Medical Center, Durham, NC. Disclosures: Author has nothing to disclose with regard to commercial support.

Received for publication May 30, 2019; accepted for publication May 31, 2019; available ahead of print July 11, 2019

Address for reprints: Nicholas D. Andersen, MD, Division of Cardiovascular and Thoracic Surgery, Duke University Medical Center, 2301 Erwin Rd, DUMC 3474, Durham, NC 27710 (E-mail: Nicholas.Andersen@ Duke.edu).

J Thorac Cardiovasc Surg 2020;159:2300-1

$0022-5223 / \$ 36.00$

Copyright $(2) 2019$ by The American Association for Thoracic Surgery

https://doi.org/10.1016/j.jtcvs.2019.05.073

The use of autologous platelet-rich plasma (aPRP) preparations to assist with blood conservation in cardiac surgery dates back to the 1970s, with mixed results achieved in several randomized, controlled trials performed during the ensuing decades. ${ }^{1,2}$ In contemporary practice, a randomized, controlled trial from the surgical group at the University of Texas at Houston found benefit with aPRP techniques in patients undergoing elective proximal aortic surgery. ${ }^{3}$ In the current issue of the Journal, a follow-up study by Sandhu and colleagues ${ }^{4}$ from the same group reports the outcomes of aPRP use in patients who underwent repair of acute type $\mathrm{A}$ aortic dissection requiring deep hypothermic circulatory arrest $\left(18^{\circ} \mathrm{C}\right)$, who are perhaps at the greatest risk of morbidity and mortality after aortic repair. Results showed that aPRP use was associated with significant reductions in perioperative blood product transfusions, ventilator times, and intensive care unit length of stay.

Although the data of Sandhu and colleagues ${ }^{4}$ are encouraging and support the intuitive notion that autologous blood product exposure is superior to allogeneic exposure, several study design issues should temper the strengths of their conclusions. The study was a retrospective, nonrandomized study spanning 11 years, and the overall rate of aPRP use was low $(21 \%)$. The striking magnitude of the treatment effect across this time span suggests that effects ascribable to era, patient acuity, or differences in surgical or perfusion technique may be lurking in the data. Only patients who were in stable enough condition to tolerate the 1 to $2 \mathrm{~L}$ of prebypass bloodletting were candidates for aPRP use, and patients who received aPRP were also noted to have shorter cardiopulmonary bypass and crossclamp times and reduced rates of coronary artery bypass grafting. Although propensity adjustment was intended to correct for some of these differences, it remains likely that the improved outcomes observed in patients who received aPRP were due in part to the use of this technique in patients who were more in more stable condition and required a lesser extent of surgery than patients who did

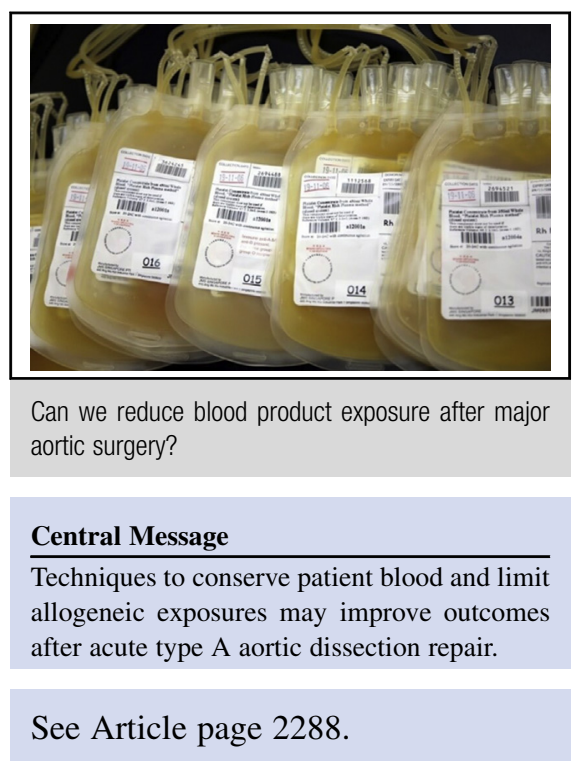

not receive aPRP. The data were also somewhat inconsistent with the results of the previously published randomized trial, where no differences in ventilator times were observed. ${ }^{3}$ Finally, no measures of platelet function were reported, and there were no differences in postoperative chest tube output. In modern practice, the effects of aPRP transfusion on outcomes may also be diminished in patients undergoing aortic repair at warmer temperatures, which is favored at many centers. ${ }^{5}$

Despite these limitations, it remains intuitive that exposing a patient to their own blood products is better than exposing them to someone else's blood products that have been processed and stored in a refrigerator for some time (Figure 1). Although more robust outcomes and cost data will likely be required to convince most blood banks and perfusion groups to adopt these practices, these data should prompt further interest in autologous donation

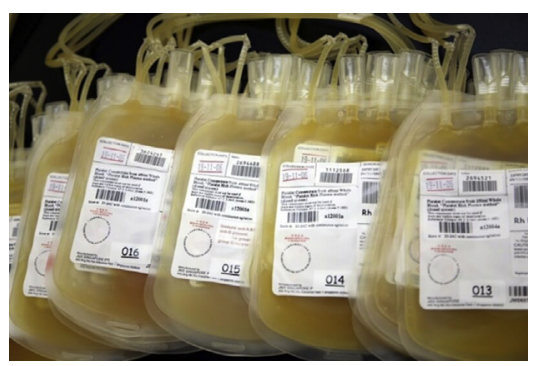

FIGURE 1. Can we reduce blood product exposure after major aortic surgery? 
practices or use of fresh whole blood as part of blood conservation strategies in cardiac surgery.

\section{References}

1. Carless PA, Rubens FD, Anthony DM, O'Connell D, Henry DA. Platelet-richplasmapheresis for minimising peri-operative allogeneic blood transfusion. Cochrane Database Syst Rev 2003;2:CD004172.

2. Mahoney CB. Platelet-rich plasmapheresis: a meta-analysis of clinical outcomes and costs. J Extra Corpor Technol. 1998;30:10-9.
3. Zhou SF, Estrera AL, Loubser P, Ignacio C, Panthayi S, Miller C 3rd, et al Autologous platelet-rich plasma reduces transfusions during ascending aortic arch repair: a prospective, randomized, controlled trial. Ann Thorac Surg. 2015; 99:1282-90.

4. Sandhu HK, Tanaka A, Dahotre S, Charlton-Ouw KM, Miller CC III, Estrera AL, et al. Propensity and impact of autologous platelet rich plasma use in acute type A dissection. J Thorac Cardiovasc Surg. 2020;159: 2288-97.e1.

5. Keeling WB, Tian DH, Leshnower BG, Numata S, Hughes GC, Matalanis G, et al Safety of moderate hypothermia with antegrade cerebral perfusion in total aortic arch replacement. Ann Thorac Surg. 2018;105:54-61. 